CLINICAL STUDY

\title{
The effect of testosterone replacement therapy on adipocytokines and $C$-reactive protein in hypogonadal men with type 2 diabetes
}

\author{
D Kapoor $^{1,3}$, S Clarke ${ }^{3}$, R Stanworth ${ }^{1,3}$, K S Channer ${ }^{2}$ and T H Jones ${ }^{1,3}$ \\ ${ }^{1}$ Centre for Diabetes and Endocrinology, Barnsley NHS Foundation Trust Hospital, Barnsley, United Kingdom, ${ }^{2}$ Department of Cardiology, \\ Royal Hallamshire Hospital, Sheffield, United Kingdom and ${ }^{3}$ Academic Unit of Diabetes, Endocrinology and Metabolism, University of Sheffield, Sheffield, \\ United Kingdom \\ (Correspondence should be addressed to T H Jones who is now at Centre for Diabetes and Endocrinology, Barnsley NHS Foundation Trust Hospital, Gawber \\ Road, Barnsley S75 2EP, United Kingdom; Email: hugh.jones@nhs.net)
}

\begin{abstract}
Objective: Serum testosterone levels are known to inversely correlate with insulin sensitivity and obesity in men. Furthermore, there is evidence to suggest that testosterone replacement therapy reduces insulin resistance and visceral adiposity in type 2 diabetic men. Adipocytokines are hormones secreted by adipose tissue and contribute to insulin resistance. We examined the effects of testosterone replacement treatment on various adipocytokines and C-reactive protein (CRP) in type 2 diabetic men. Design: Double-blinded placebo-controlled crossover study in 20 hypogonadal type 2 diabetic men. Patients were treated with testosterone (sustanon $200 \mathrm{mg}$ ) or placebo intramuscularly every 2 weeks for 3 months in random order followed by a washout period of 1 month before the alternate treatment phase.

Methods: Leptin, adiponectin, resistin, tumour necrosis factor- $\alpha$ (TNF- $\alpha$ ), interleukin (IL)-6 and CRP levels were measured before and after each treatment phase. Body mass index (BMI) and waist circumference were also recorded.

Results: At baseline, leptin levels significantly correlated with BMI and waist circumference. There was a significant inverse correlation between baseline IL- 6 and total testosterone $(r=-0.68 ; P=0.002)$ and bioavailable testosterone levels $(r=-0.73 ; P=0.007)$. CRP levels also correlated significantly with total testosterone levels $(r=-0.59 ; P=0.01)$. Testosterone treatment reduced leptin $(-7141.9 \pm 1461.8 \mathrm{pg} / \mathrm{ml} ; \quad P=0.0001)$ and adiponectin levels $(-2075.8 \pm 852.3 \mathrm{ng} / \mathrm{ml}$; $P=0.02$ ). There was a significant reduction in waist circumference. No significant effects of testosterone therapy on resistin, TNF- $\alpha$, IL- 6 or CRP levels were observed.

Conclusion: Testosterone replacement treatment decreases leptin and adiponectin levels in type 2 diabetic men. Moreover, low levels of testosterone in men are associated with pro-inflammatory profile, though testosterone treatment over 3 months had no effect on inflammatory markers.
\end{abstract}

European Journal of Endocrinology 156 595-602

\section{Introduction}

The primary function of adipose tissue has traditionally been to store energy, but following the past decade it is now considered to be an endocrine organ secreting various peptides termed adipocytokines. Some of these adipocytokines, such as leptin, adiponectin, tumour necrosis factor- $\alpha$ (TNF- $\alpha$ ) and interleukin (IL)-6, are known to contribute to the development of insulin resistance $(1,2)$. Weight loss has been shown to induce favourable changes in serum adipocytokines (3).

Leptin is an adipocyte-secreted protein product of the $o b$ gene. Leptin levels increase in direct proportion to the adipose tissue mass and leptin production is higher in s.c. than visceral fat depots (4). In contrast, adiponectin levels are significantly lower in obese subjects than in lean (5). Moreover, adiponectin is produced mainly by visceral adipose tissue (6) and correlates negatively with insulin resistance (7). Resistin, on the other hand, is another adipocytokine which has been shown to be elevated in rodent obesity models, but its role in humans is less clear as epidemiological studies in humans have not shown a constant link between resistin and adiposity or insulin resistance $(2,8)$. Adipose tissue TNF- $\alpha$ and IL- 6 are also known to correlate with obesity $(1,2)$. In contrast to TNF- $\alpha$, adipose tissue releases IL-6 into circulation and thus the levels of IL-6 are much higher in blood than TNF- $\alpha$ levels (9). Both TNF- $\alpha$ and IL-6 are also pro-inflammatory cytokines and are elevated in infection and inflammation. There is accumulating evidence to suggest that low testosterone levels in men are associated with reduced insulin 
sensitivity and type 2 diabetes (10). Studies have demonstrated that there is a higher prevalence of hypogonadism in diabetic men when compared with non-diabetic subjects (11-14). We have previously shown that testosterone replacement therapy reduces insulin resistance and improves glycaemic control in hypogonadal men with type 2 diabetes (15).

Visceral obesity is an important risk factor for the development of insulin resistance and type 2 diabetes. Studies have reported that free testosterone levels are low in obese men and inversely correlate with the degree of obesity $(16,17)$. There is an increased deposition of abdominal adipose tissue in hypogonadal subjects, which in turn leads to a further reduction in testosterone concentrations through conversion to oestradiol by aromatase, hence facilitating fat deposition and a greater degree of hypogonadism $(10,18)$. Testosterone therapy has been shown to reduce visceral fat mass in middle-aged obese (19) and type 2 diabetic men (15). Moreover, Snyder et al. (20) have reported a reduction in fat mass in elderly men with testosterone replacement treatment.

Even though testosterone replacement therapy has been shown to have favourable effects on obesity and insulin resistance in hypogonadal men, as elucidated earlier, few studies have examined its effects on adipocytokines. An inverse relationship has been reported between serum testosterone and leptin concentrations in men (21-23) and testosterone replacement therapy has been found to decrease serum leptin levels in hypogonadal men $(24,25)$. Testosterone therapy has also been shown to reduce adiponectin concentrations in both sham-operated and castrated mice as well as in cultured adipocytes (26). Two studies, one in hypogonadal men and another in healthy men in whom hypogonadism was induced with gonadotrophin-releasing hormone antagonist, have similarly shown that testosterone treatment suppresses adiponectin levels $(27,28)$. Similarly, testosterone replacement therapy has been reported to reduce levels of circulating TNF- $\alpha$ in hypogonadal men, the majority of whom had coronary artery disease (29). However, Lambert et al. (30) found no effect on TNF- $\alpha$ or leptin in elderly eugonadal men ingesting megesterol acetate who were treated with testosterone, resistance training or both. In another study, elderly men with hypogonadism induced with gonadotrophin-releasing agonists developed significant increases in serum TNF- $\alpha$ and IL- 6 (31). However, in the same study, although testosterone treatment reduced the cytokines, this was not statistically significant. A recent study in type 2 diabetic men with partial androgen deficiency showed that testosterone treatment reduces ex vivo production of IL-1 $\beta$, IL-6 and TNF- $\alpha$ by antigen-presenting cells (32).

CRP is a non-specific acute phase protein produced by the liver that has traditionally been used to diagnose and monitor acute inflammation/infection. It is now considered an important marker of increased cardiovascular risk in both men and women (33). Elevated levels of CRP have also been shown to predict the development of type 2 diabetes (34).

To our knowledge, there have been no studies examining the effects of testosterone replacement treatment on adipocytokines and CRP in type 2 diabetic men. The aim of this study was to assess the effect of testosterone therapy on leptin, adiponectin, resistin, TNF- $\alpha$, IL-6 and CRP levels in hypogonadal men with type 2 diabetes. This is a supplementary to our recently published study in the European Journal of Endocrinology demonstrating a beneficial effect of testosterone replacement treatment on insulin resistance, glycaemic control and visceral adiposity in type 2 diabetic men (15).

\section{Subjects and methods}

This was a double-blind placebo-controlled crossover study of testosterone treatment in hypogonadal type 2 diabetic men, performed at the Centre for Diabetes and Endocrinology, Barnsley NHS Foundation Trust Hospital, Barnsley, UK. The primary outcomes were changes in leptin, adiponectin, resistin, TNF- $\alpha$ and IL- 6 levels. The secondary outcomes were changes in anthropometric measurements, including waist circumference, body mass index (BMI), percentage body fat and CRP. The trial had a 7-month duration in which patients had two treatment phases of 3 months, each with a washout period of 1 month in between. Each patient was randomised to receive either placebo or testosterone therapy first and after the washout period patients crossed over to the alternate therapy.

Subjects were hypogonadal men with type 2 diabetes above the age of 30 years. All patients gave written informed consent and the local research ethics committee approved the protocol. Inclusion criteria were type 2 diabetic men with $\mathrm{HbAlc}$ up to $9.5 \%$ showing no significant symptoms of hyperglycaemia. Hypogonadism was defined as total testosterone level $<12 \mathrm{nmol} / \mathrm{l}$ (35) and bioavailable testosterone $<4 \mathrm{nmol} / \mathrm{l}$ (36) (on two separate occasions) with symptoms of hypogonadism (positive score in the Androgen Deficiency in the Ageing Male questionnaire) (37). Patients were excluded if they had any inflammatory disease or infection with an elevation of $\mathrm{CRP}>10 \mathrm{mg} / \mathrm{l}$, those already on hormone therapy and if they had any contraindication to testosterone therapy such as elevation of prostate-specific antigen (PSA) beyond the age-adjusted normal range. TNF- $\alpha$ and IL- 6 were also not measured in those patients who had an elevation of CRP $>10 \mathrm{mg} / \mathrm{l}$ following treatment with either placebo or testosterone.

\section{Randomisation and drug treatment}

Patients were randomised to 'testosterone first' or 'placebo first' using a computer-generated random 
number. Treatment was with sustanon $200 \mathrm{mg}$ ( $30 \mathrm{mg}$ testosterone propionate, $60 \mathrm{mg}$ testosterone phenylpropionate, $60 \mathrm{mg}$ testosterone isocaproate and $100 \mathrm{mg} / \mathrm{ml}$ testosterone decanoate, Organon laboratories, Cambridge, UK), a depot preparation of testosterone given by deep i.m. injection. Intramuscular injections were given once every 2 weeks; patients received a total of six injections in each phase. The final assessment in each treatment phase was 12-14 days after previous injection. This regimen is commonly used as standard physiological testosterone replacement therapy in men with androgen deficiency and represents 3 months of testosterone treatment. Placebo was $0.9 \%$ normal saline. Drugs were drawn in identical syringes and given by a research nurse in a separate clinical room away from the patient and the doctor assessing the patient.

\section{Assessment}

Patients were initially screened with a questionnaire detailing their medical history and their concomitant medications were noted. Assessments were always made between 0800 and $1000 \mathrm{~h}$ after an overnight fast. All concomitant oral hypoglycaemic, anti-hypertensive and lipid-lowering medications were permitted and continued throughout the study without dose adjustment. However, those patients who were on insulin were permitted to make insulin dose adjustments to avoid hypoglycaemia. Subjects' height and weight were recorded and BMI was calculated using the equation $\left(\mathrm{BMI}=\right.$ weight $(\mathrm{kg}) /$ height $\left.(\mathrm{m})^{2}\right)$. Waist circumference was measured - waist was defined as the point midway between the iliac crest and the costal margin (lower rib). Percentage body fat was also recorded in the fasting state by bioelectrical impedance technique using TANITA BF-300 body fat analyser (TANITA Corporation, Tokyo, Japan).

Serum samples were obtained by centrifugation (10 min at 3500 r.p.m.) and immediately frozen at $-20{ }^{\circ} \mathrm{C}$ pending further analysis. Total testosterone and sex hormone-binding globulin were measured by ELISA technique (DRG Diagnostics, Marburg, Germany). Bioavailable testosterone was determined by a modification of the ammonium sulphate precipitation method described by Tremblay and Dube (38).

Leptin, adiponectin, resistin, TNF- $\alpha$ and IL- 6 were measured by ELISA technique (R\&D Systems, Abingdon, UK). The intra- and inter-assay coefficients of variation were $<4$ and $<6 \%$ for leptin, $<5$ and $<7 \%$ for adiponectin, $<6$ and $<10 \%$ for adiponectin, $<9$ and $<17 \%$ for TNF- $\alpha,<8$ and $<10 \%$ for IL- 6 and $<7$ and $<15 \%$ for CRP respectively.

\section{Statistical analysis}

Data were analysed using GraphPad Instat package (version 3.05). All data were tested against normal distribution using Kolmogorov-Smirnov test. The data are presented as mean \pm s.E.M. unless indicated otherwise. The data were initially examined to exclude treatment/period interaction by ensuring that the baseline data of the treatment group (placebo and testosterone) were not statistically different, using the $t$-test between the baseline values in each case. The primary and secondary outcomes were compared by analysis of the $\delta$ between group analysis of the difference with placebo versus testosterone using $t$-test. As serum levels of IL-6 were non-parametric, the Wilcoxon matched paired test was used. The impact of various anthropometric measurements and testosterone levels on adipocytokines was determined by linear regression and correlation. Results were considered statistically significant at $P<0.05$.

\section{Results}

The baseline data are presented in Table 1 . The sample comprised a group of 20 hypogonadal men with type 2 diabetes. Four patients from the original study were excluded as there was insufficient sample to analyse all the adipocytokines. Fourteen were on oral hypoglycaemic agents and six were on insulin treatment. Eight patients had primary hypogonadism, of which one was diagnosed with Klinefelter's syndrome, and two had secondary hypogonadism who were further investigated and found to have normal pituitary hormones and magnetic resonance imaging pituitary. Fourteen men had a mixed picture of hypogonadism with low testosterone levels and gonadotrophins within normal range. There were no adverse effects of treatment on

Table 1 Baseline characteristics of the population.

\begin{tabular}{|c|c|c|}
\hline Parameter & Mean \pm s.E.M. & Sample range \\
\hline Age (years) & $63.15 \pm 1.5$ & $52-76$ \\
\hline Total testosterone $(\mathrm{nmol} / \mathrm{l})$ & $7.54 \pm 0.55$ & $2.78-10.7$ \\
\hline Sex hormone-binding globulin ( $\mathrm{nmol} / \mathrm{l})$ & $27.01 \pm 2.89$ & $11.67-63.45$ \\
\hline Bioavailable testosterone $(\mathrm{nmol} / \mathrm{l})$ & $2.48 \pm 0.19$ & $0.84-3.87$ \\
\hline Leptin $(\mathrm{pg} / \mathrm{ml})$ & $17774.27 \pm 1971$ & $5366-36357$ \\
\hline Adiponectin (ng/ml) & $8468.63 \pm 1392$ & $1163-23209$ \\
\hline Resistin (ng/ml) & $20.59 \pm 1.66$ & $8.75-35.66$ \\
\hline $\mathrm{TNF}-\alpha(\mathrm{pg} / \mathrm{ml})$ & $2.1 \pm 0.15$ & $1.09-3.52$ \\
\hline $\mathrm{IL}-6(\mathrm{pg} / \mathrm{ml})$ & $1.88 \pm 0.29$ & $0.77-5.17$ \\
\hline $\mathrm{CRP}(\mathrm{mg} / \mathrm{ml})$ & $4.93 \pm 0.76$ & $0.44-8.7$ \\
\hline BMI & $33.28 \pm 1.02$ & $26.4-45$ \\
\hline Waist circumference $(\mathrm{cm})$ & $115.95 \pm 2.72$ & $98-141$ \\
\hline Percentage body fat & $33.97 \pm 1.2$ & $24.3-45.2$ \\
\hline HbA1c (\%) & $7.28 \pm 0.19$ & $5.8-9.4$ \\
\hline \multicolumn{3}{|l|}{ Medications $^{\mathrm{a}}$} \\
\hline None (diet only) & 3 & \\
\hline Metformin & 4 & \\
\hline Metformin + gliclazide & 2 & \\
\hline Metformin + rosiglitazone & 3 & \\
\hline $\begin{array}{l}\text { Metformin + gliclazide }+ \\
\text { rosiglitazone }\end{array}$ & 2 & \\
\hline Insulin + metformin & 4 & \\
\hline Insulin & 2 & \\
\hline
\end{tabular}

aPatients had been stabilised on these medications for at least 6 months prior to the study and no dose adjustments of oral hypoglycaemics were made during the study. 
haematological, PSA or biochemical parameters. The results are summarised in Table 2 . The baseline values of each adipocytokine fraction in the placebo and testosterone phases were not statistically different. TNF- $\alpha$ and IL- 6 were not measured in three patients as CRP was $>10 \mathrm{mg} / \mathrm{l}$ after treatment with placebo and testosterone.

\section{Leptin}

Leptin levels were significantly correlated with both BMI $(r=0.707 ; P<0.001)$ and waist circumference $(r=0.783 ; P<0.001)$ at baseline. No significant associations were seen between leptin concentrations and total testosterone, bioavailable testosterone or percentage body fat. There was a significant reduction in leptin levels with testosterone treatment when compared with placebo. The mean treatment effect and 95\% confidence intervals of testosterone on leptin concentrations were reduced $(-7141.9 \pm 1461.8 \mathrm{pg} / \mathrm{ml}, P=0.0001$; range -4082.4 to -10201 ) when compared with placebo.

\section{Adiponectin}

There was a significant decrease in adiponectin concentrations with testosterone therapy $(-2075.8 \pm$ $852.28 \mathrm{ng} / \mathrm{ml}, P=0.02$; range -292.03 to -3859.6$)$. The changes in adiponectin levels correlated inversely with changes in BMI observed with testosterone treatment $(r=-0.44 ; P=0.04)$. However, no significant correlations were observed between baseline adiponectin levels and BMI, waist circumference or testosterone concentrations or between changes in adiponectin levels and waist circumference or percentage body fat.

\section{Resistin}

No significant effect of testosterone therapy on resistin levels was observed. Moreover, there were no significant correlations between baseline resistin levels and BMI, waist circumference or testosterone concentrations.

\section{IL-6}

There was a significant inverse correlation between baseline IL-6 and total testosterone $(r=-0.68 ; P=$ $0.002)$ and bioavailable testosterone levels $(r=-0.73$; $P=0.007$; Fig. 1). No associations were seen between IL-6 concentrations and BMI or waist circumference. There was no significant effect of testosterone treatment on IL-6 levels $(-1.32 \pm 1.8 \mathrm{pg} / \mathrm{ml} ; P=0.28)$.

\section{TNF- $\alpha$}

No significant changes were observed in TNF- $\alpha$ levels following testosterone treatment. Moreover, TNF- $\alpha$ levels were not correlated with BMI, waist circumference or testosterone concentrations.

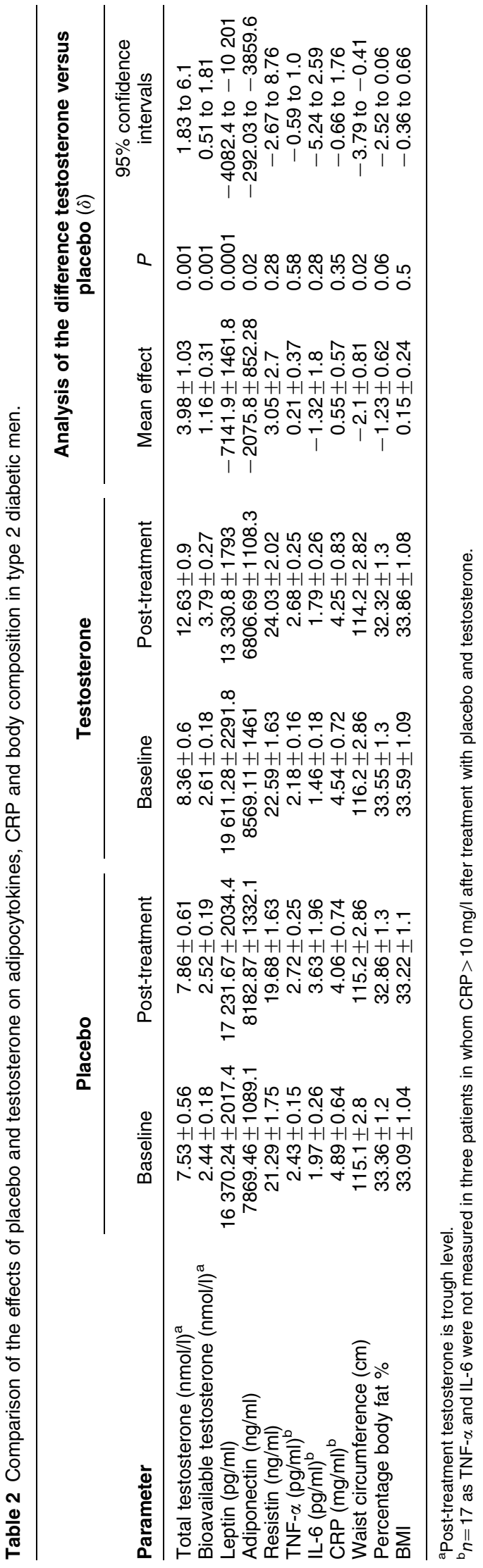

www.eje-online.org 

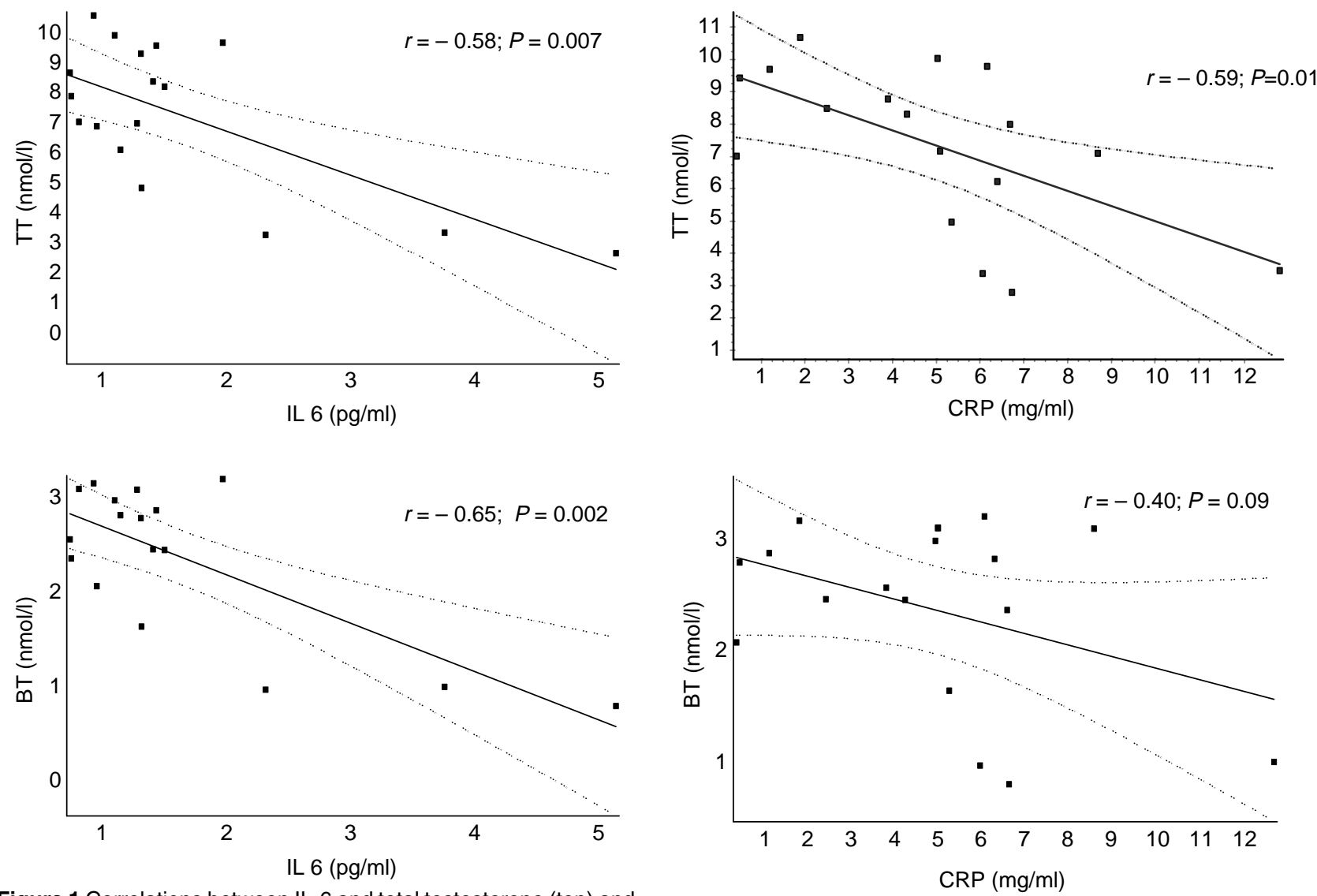

Figure 1 Correlations between IL-6 and total testosterone (top) and between IL-6 and bioavailable testosterone (bottom).

\section{CRP}

There was a significant inverse correlation between baseline CRP and total testosterone $(r=-0.59$; $P=0.01$; Fig. 2). There was also an inverse trend between CRP and bioavailable testosterone levels which did not reach statistical significance $(r=-0.40$; $P=0.09$ ). No associations were seen between CRP concentrations and either BMI or waist circumference. There was no significant effect of testosterone treatment on CRP levels $(0.55 \pm 0.57 \mathrm{mg} / \mathrm{l} ; P=0.35)$.

\section{Body composition}

There was a significant reduction in waist circumference $(-2.1 \pm 0.81 \mathrm{~cm}, P=0.02$; range -3.79 to -0.41 ) following testosterone treatment. Percentage body fat also decreased and approached statistical significance $(-1.23 \pm 0.62 ; P=0.06)$. No significant changes were observed in BMI.

\section{Discussion}

This is the first study to demonstrate that testosterone replacement therapy decreases leptin and adiponectin

Figure 2 Correlations between CRP and total testosterone (top) and between CRP and bioavailable testosterone (bottom).

levels in hypogonadal men with type 2 diabetes. There is also a significant reduction in visceral adiposity. No significant changes were observed in resistin, TNF- $\alpha$, IL-6 or CRP levels. However, baseline testosterone levels correlated with IL- 6 and CRP.

The main role of leptin is to regulate energy intake and expenditure mediated predominantly by its action on the hypothalamus. Leptin levels are high in obese humans and it has been suggested that obesity is caused by resistance to leptin. In our study, leptin levels correlated with both BMI and waist circumference. Others have similarly shown an association in nondiabetic individuals $(39,40)$. We have also shown that testosterone replacement treatment suppresses leptin levels in hypogonadal type 2 diabetic men. Testosterone administration has been shown to decrease leptin levels in healthy men with low plasma total testosterone (41) and also in young and old hypogonadal men $(24,25)$. Furthermore, testosterone substitution in hypogonadal men has been found to prevent age-dependent increases in leptin as seen in healthy ageing men (42). However, we found no correlation between baseline leptin and androgen levels. Similarly, Sih et al. (25) found no correlation between leptin and testosterone levels, though they did report a reduction of leptin levels 
with testosterone replacement therapy in elderly men. Haffner et al. (43) also showed no correlation between leptin and sex hormones in middle-aged men. However, it has been reported by other researchers that there is an inverse association between serum leptin and testosterone levels (21-23). The differences in the observations could be due to the different populations studied and multiple factors involved in regulation of leptin secretion.

The mechanisms by which testosterone reduces leptin levels are uncertain. Testosterone treatment has been shown to reduce adipose tissue mass as mentioned. In our study, testosterone treatment reduced visceral adiposity and percentage body fat. Thus, leptin levels could decrease with the reduction in volume of adipose tissue. Furthermore, the apparent state of leptin resistance seen in obesity and probably hypogonadal state is possibly corrected by testosterone replacement treatment, thus restoring the normal responsiveness of hypothalamus to leptin resulting in further weight loss and reduced leptin levels. Another possible mechanism is a direct suppressive effect of testosterone on $o b$ gene expression. Adipocytes carry androgen receptors (44), and testosterone and dihydrotestosterone have been shown to suppress leptin secretion and leptin mRNA in primary culture of human adipocytes (45).

This study has found that testosterone therapy reduces adiponectin levels in diabetic men. This is comparable with a study by Lanfranco et al. (27) who reported that testosterone treatment for 6 months in young hypogonadal non-diabetic men reduced adiponectin levels. Similarly in another study in healthy men, experimentally induced testosterone deficiency resulted in an elevation in serum adiponectin and the addition of testosterone prevented this rise (28). The mechanism by which testosterone influences adiponectin is unclear. Testosterone treatment reduces plasma adiponectin in both sham-operated and castrated mice and decreases adiponectin secretion in cultured adipocytes (26). Low adiponectin levels are associated with obesity, insulin resistance and cardiovascular disease $(1,7)$. However, testosterone replacement therapy has been shown to have favourable effects on insulin resistance and other cardiovascular risk factors in men (10). The effect of testosterone on adiponectin could possibly be explained by its effects on body composition. The reduction in fat mass observed with testosterone therapy could possibly result in decreased secretion of adiponectin by adipocytes. However, a longer study over 36 months in older men showed that testosterone therapy decreased fat mass and leptin levels without affecting adiponectin concentrations (46). A plausible explanation for this is that the beneficial effect of testosterone treatment on body composition possibly increases adiponectin levels, but this is compensated by a direct negative effect of testosterone on adiponectin gene and protein expression (46).

This is the first study to examine the effect of testosterone treatment on resistin levels in men. It has been suggested that testosterone is a regulator of resistin in male mice (47). We found no effect of testosterone treatment on resistin. The role of resistin in insulin resistance and adiposity in humans is also not clear and requires further evaluation.

Our study showed no effect of testosterone therapy on TNF- $\alpha$ levels in diabetic men. This finding is in contrast to another study by our group where we found a significant reduction in TNF- $\alpha$ levels in hypogonadal men (29). However, in that study, majority of the patients had coronary artery disease and atherosclerosis is associated with increased pro-inflammatory cytokines such as TNF- $\alpha$. Only five patients in our study had ischaemic heart disease and this could explain the lack of effect of testosterone on TNF- $\alpha$ observed in our study.

We found that IL- 6 and CRP concentrations inversely correlated with baseline testosterone levels in men. A recent study in older men has reported an inverse relationship between soluble IL- 6 receptor and testosterone levels but not with any other inflammatory marker (48). Yang et al. (49) reported that free testosterone levels correlated negatively with CRP. No significant effect of testosterone treatment on IL- 6 levels or CRP was seen in our study. Others have similarly found no effect on IL-6 levels with testosterone therapy (29). Two studies in healthy men have found no effect of androgen therapy on CRP $(50,51)$. Both these studies, similar to the present study, were short-duration studies over 3-6 months and the long-term effect of testosterone treatment on CRP has not been investigated.

In conclusion, we have demonstrated that testosterone replacement therapy decreases both leptin and adiponectin levels in hypogonadal men with type 2 diabetes. Testosterone therapy has been shown to improve insulin resistance, visceral adiposity and glycaemic control in hypogonadal men with type 2 diabetes (15). The fall in leptin levels confirms the beneficial effect of testosterone replacement therapy in reducing visceral adiposity. Adiponectin is known to positively correlate with insulin resistance but shortterm testosterone replacement therapy appears to decrease its secretion as in this study. Moreover, this study also showed that low levels of testosterone in men are associated with inflammation, though testosterone treatment over 3 months had no effect on inflammatory markers. Longer term studies would be required to elucidate further any effect of testosterone on inflammatory state.

\section{Acknowledgements}

This project was funded by a small projects grant from Barnsley NHS Foundation Trust Hospital Research and Development Department. We would like to thank Emma Goodwin for her help in giving the testosterone and placebo injections. We would also like to thank Prof. 
Mike Campbell from Sheffield University for his help with statistical analysis.

\section{References}

1 Pittas AG, Joseph NA \& Greenberg A. Adipocytokines and insulin resistance. Journal of Clinical Endocrinology and Metabolism 2004 89 447-452.

2 Kershaw EE \& Flier JS. Adipose tissue as an endocrine organ. Journal of Clinical Endocrinology and Metabolism 2004892548 2556.

3 Valsamakis G, McTernan PP, Chetty R, Al Daghri N, Field A, Hanif W, Barnett AA \& Kumar S. Modest weight loss and reduction in waist circumference after medical treatment are associated with favourable changes in serum adipocytokines. Metabolism 200453 430-434.

4 Mantzoros CS. The role of leptin in human obesity and disease: a review of current evidence. Annals of Internal Medicine 1999130 671-680.

5 Arita Y, Kihara S, Ouchi N, Takahashi M, Maeda K, Miyagawa J, Hotta K, Shimomura I, Nakamura T, Miyaoka K, Kuriyama H, Nishida M, Yamashita S, Okubo K, Matsubara K, Muraguchi M, Ohmoto Y, Funahashi T \& Matsuzawa Y. Paradoxical decrease of an adipose-specific protein, adiponectin, in obesity. Biochemical and Biophysical Research Communications 1999257 79-83.

6 Motoshima H, Wu X, Sinha MK, Hardy VE, Rosato EL, Barbot DJ, Rosato FE \& Goldstein BJ. Differential regulation of adiponectin secretion from cultured human omental and subcutaneous adipocytes: effects of insulin and rosiglitazone. Journal of Clinical Endocrinology and Metabolism 200287 5662-5667.

7 Weyer C, Funahashi T, Tanaka S, Hotta K, Matsuzawa Y, Pratley RE \& Tataranni PA. Hypoadiponectinemia in obesity and Type 2 diabetes: close association with insulin resistance and hyperinsulinemia. Journal of Clinical Endocrinology and Metabolism 200186 1930-1935.

8 Hasegawa G, Ohta M, Ichida Y, Obayashi H, Shigeta M, Yamasaki M, Fukui M, Yoshikawa T \& Nakkamura N. Increased serum resistin levels in patients with type 2 diabetes are not linked with markers of insulin resistance and adiposity. Acta Diabetologica 200542 104-109.

9 Mohamed-Ali V, Goodrick S, Rawesh A, Katz DR, Miles JM, Yudkin JS, Klein S \& Coppack SW. Subcutaneous adipose tissue releases interleukin-6, but not tumour necrosis factor alpha, in vivo. Journal of Clinical Endocrinology and Metabolism $1997 \mathbf{8 2}$ 4196-4200.

10 Kapoor D, Malkin CJ, Channer KS \& Jones TH. Androgens, insulin resistance and vascular disease in men. Clinical Endocrinology 200563 239-250.

11 Barrett-Connor E, Khaw KT \& Yen SS. Endogenous sex hormone levels in older men with diabetes mellitus. American Journal of Epidemiology 1990132 895-901.

12 Barrett-Connor E. Lower endogenous androgen levels and dyslipidemia in men with non insulin-dependent diabetes mellitus. Annals of Internal Medicine 1992117 807-811.

13 Andersson B, Marin P, Lissner L, Vermeulen A \& Bjorntorp P. Testosterone concentrations in women and men with NIDDM. Diabetes Care 199417 405-411.

14 Dhindsa S, Prabhakar S, Sethi M, Bandyopadhyay A, Chaudhuri A \& Dandona P. Frequent occurrence of hypogonadotropic hypogonadism in Type 2 diabetes. Journal of Clinical Endocrinology and Metabolism $2004895462-5468$.

15 Kapoor D, Goodwin E, Channer KS \& Jones TH. Testosterone reduces insulin resistance, glycaemic control, visceral adiposity and hypercholesterolaemia in hypogonadal men with Type 2 diabetes. European Journal of Endocrinology 2006154 899-906.

16 Zumoff B, Strain GW, Miller LK, Rosner W, Senie R, Seres DS \& Rosenfeld RS. Plasma free and non sex-hormone-binding-globulin- bound testosterone are decreased in obese men in proportion to their degree of obesity. Journal of Clinical Endocrinology and Metabolism 199071 929-931.

17 Haffner SM, Valdez RA, Stern MP \& Katz MS. Obesity, body fat distribution and sex hormones in men. International Journal of Obesity 199317 643-649.

18 Cohen PG. The hypogonadal-obesity cycle. Medical Hypotheses 199952 49-51.

19 Marin P, Holmang S, Jonsson L, Sjostrom L, Kvist H, Holm G, Lindstedt $\mathrm{G} \&$ Bjorntorp P. The effects of testosterone treatment on body composition and metabolism in middle-aged obese men. International Journal of Obesity and Related Metabolic Disorders 1992 16 991-997.

20 Snyder PJ, Peachey H, Hannoush P, Berlin JA, Loh L, Lenrow DA, Holmes JH, Dlewati A, Santanna J, Rosen CJ \& Strom BL. Effect of testosterone treatment on body composition and muscle strength in men over 65 years of age. Journal of Clinical Endocrinology and Metabolism 199989 2647-2653.

21 Luukkaa V, Pesonen U, Huhtaniemi I, Lehtonen A, Tilvis R, Tuomilehto J, Koulu M \& Huupponen R. Inverse correlation between serum testosterone and leptin in men. Journal of Clinical Endocrinology and Metabolism 199883 3243-3246.

22 Behre HM, Simoni M \& Nieschlag E. Strong association between serum levels of leptin and testosterone in men. Clinical Endocrinology $1997 \mathbf{4 7} 237-240$.

23 Isidori AM, Caprio M, Strollo F, Moretti C, Frajese G, Isidori A \& Fabbri A. Leptin and androgens in male obesity: evidence for leptin contribution to reduced androgen levels. Journal of Clinical Endocrinology and Metabolism 199984 3673-3680.

24 Jockenhovel F, Blum WF, Vogel E, Englaro P, Muller-Wieland D, Reinwein D, Rascher W \& Krone W. Testosterone substitution normalizes elevated serum leptin levels in hypogonadal men. Journal of Clinical Endocrinology and Metabolism $1997 \mathbf{8 2}$ 2510-2513.

25 Sih R, Morley JE, Kaiser FE, Perry HM III, Patrick P \& Ross C. Testosterone replacement in older hypogonadal men: a 12-month randomised controlled trial. Journal of Clinical Endocrinology and Metabolism 199782 1659-1660.

26 Nishizawa H, Shimomura I, Kishida K, Maeda N, Kuriyama H, Nagaretani H, Matsuda M, Kondo H, Furuyama N, Kihara S, Nakamura T, Tochino Y, Funahashi T \& Matsuzawa Y. Androgens decrease plasma adiponectin, an insulin sensitising adipocytederived protein. Diabetes $2002512734-2741$.

27 Lanfranco F, Zitzmann M, Simoni M \& Nieschlag E. Serum adiponectin levels in hypogonadal men: influence of testosterone replacement therapy. Clinical Endocrinology 200460 500-507.

28 Page ST, Herbst KL, Amory JK, Coviello AD, Anawalt BD, Matsumoto AM \& Bremner WJ. Testosterone administration suppresses adiponectin levels in men. Journal of Andrology 2005 26 1-13.

29 Malkin CJ, Pugh PJ, Kapoor D, Jones RD, Channer KS \& Jones TH. The effect of testosterone replacement on endogenous inflammatory cytokines and lipid profiles in hypogonadal men. Journal of Clinical Endocrinology and Metabolism $2004893313-3318$.

30 Lambert CP, Sullivan DH \& Evans WJ. Effects of testosterone replacement and/or resistance training on interleukin-6, tumor necrosis factor alpha and leptin in elderly men ingesting megestrol acetate: a randomised controlled trial. Journals of Gerontology. Series A, Biological Sciences and Medical Sciences 200358 165-170.

31 Khosla S, Atkinson EJ, Dunstan CR \& O'Fallon WM. Effect of estrogen versus testosterone on circulating osteoprotegerin and other cytokine levels in normal elderly men. Journal of Clinical Endocrinology and Metabolism 200287 1550-1554.

32 Corrales JJ, Almeida M, Burgo R, Mories MT, Miralles JM \& Orfao A. Androgen-replacement therapy depresses the ex vivo production of inflammatory cytokines by circulating antigenpresenting cells in aging type- 2 diabetic men with partial androgen deficiency. Journal of Endocrinology $2006 \quad 189$ 595-604. 
33 Rifai N \& Ridker PM. High-sensitivity C-reactive protein: a novel and promising marker of coronary disease. Clinical Chemistry 200147 403-411.

34 Pradhan AD, Manson JE, Rifai N, Buring JE \& Ridker PM. Creactive protein, interleukin- 6 and risk of developing type 2 diabetes. JAMA $2001286327-334$.

35 Nieschlag E, Swerdloff R, Behre HM, Gooren LJ, Kaufman JM, Legros JJ, Lunenfeld B, Morley JE, Schulman C, Wang C, Weidner $\mathrm{W} \& \mathrm{Wu} \mathrm{FC}$. Investigation, treatment and monitoring of late-onset hypogonadism in males: ISA, ISSAM, and EAU recommendations. International Journal of Andrology $2005 \mathbf{2 8}$ $125-127$.

36 Kapoor D, Aldred H, Clarke S, Channer KS, Jones TH. Clinical and biochemical assessment of hypogonadism in men with Type 2 diabetes mellitus - correlations with bioavailable testosterone and visceral adiposity. Diabetes Care 2007 (in press).

37 Morley JE, Charlton E, Patrick P, Kaiser FE, Cadeau P, McCready D \& Perry HM III. Validation of a screening questionnaire for androgen deficiency in aging males. Metabolism $2000 \mathbf{4 9}$ 1239-1242.

38 Tremblay RR \& Dube JY. Plasma concentrations of free and nonTeBG bound testosterone in women on oral contraceptives. Contraception 197410 599-605.

39 Gomez JM, Maravall FJ, Gomez N, Navarro MA, Casamitjana R \& Soler J. Interactions between serum leptin, the insulin-like growth factor-1 system, and sex, age, anthropometric and body composition variables in a healthy population randomly selected. Clinical Endocrinology 200358 213-219.

40 Abdella NA, Mojiminiyi OA, Moussa MA, Zaki M, Al Mohammedi H, Al Ozairi ES \& Al Jebely S. Plasma leptin concentration in patients with Type 2 diabetes: relationship to cardiovascular disease risk factors and insulin resistance. Diabetic Medicine 200522 278-285.

41 Simon D, Charles MA, Lahlou N, Nahoul K, Oppert JM, GouaultHeilmann M, Lemort N, Thibult N, Joubert E, Balkau B \& Eschwege E. Androgen therapy improves insulin sensitivity and decreases leptin level in healthy adult men with low plasma total testosterone. Diabetes Care 200124 2149-2151.

42 Rolf C, Eckardstein SV, Koken U \& Nieschlag E. Testosterone substitution of hypogonadal men prevents the age-dependent increases in body mass index, body fat and leptin seen in healthy ageing men: results of a cross-sectional study. European Journal of Endocrinology 2002146 505-511.
43 Haffner SM, Miettinen H, Karhapaa P, Mykkanen L \& Laakso M. Leptin concentrations, sex hormones and cortisol in nondiabetic men. Journal of Clinical Endocrinology and Metabolism $1997 \mathbf{8 2}$ 1807-1809.

44 Bjorntorp P. The regulation of adipose tissue distribution in humans. International Journal of Obesity and Related Metabolic Disorders 199620 291-302.

45 Wabitsch M, Blum WF, Muche R, Braun M, Hube F, Rascher W, Heinze E, Teller W \& Hauner H. Contribution of androgens to the gender difference in leptin production in obese children and adolescents. Journal of Clinical Investigation 199715 808-813.

46 Page ST, Amory JK, Bowman FD, Anawalt BD, Matsumoto AM, Bremner WJ \& Tenover JL. Exogenous testosterone alone or with Finasteride increases physical performance, grip strength and lean body mass in older men with low serum testosterone. Journal of Clinical Endocrinology and Metabolism $2005901502-1510$.

47 Ling C, Kindblom J, Wennbo H \& Billig H. Increased resistin expression in the adipose tissue of male prolactin transgenic mice and in male mice with elevated androgen levels. FEBS Letters $20015 \mathbf{5 0 7} 147-150$.

48 Maggio M, Basaria S, Ble A, Lauretani F, Bandinelli S, Ceda GP, Valenti G, Ling SM \& Ferrucci L. Correlation between testosterone and the inflammatory marker soluble interleukin- 6 receptor in older men. Journal of Clinical Endocrinology and Metabolism 2006 91 345-347.

49 Yang YM, Lv XY, Huang WD, Xu ZR \& Wu LJ. Study of androgen and atherosclerosis in old age male. Journal of Zhejiang University Science B $20056931-935$.

50 Singh AB, Hsia S, Alaupovic P, Sinha-Hikim I, Woodhouse L, Buchanan TA, Shen R, Bross R, Berman N \& Bhasin S. The effects of varying doses of testosterone on insulin sensitivity, plasma lipids, apolipoproteins and C-reactive protein in healthy young men. Journal of Clinical Endocrinology and Metabolism $2002 \mathbf{8 7}$ 136-143.

51 Ng MK, Liu PY, Williams AJ, Nakhla S, Ly LP, Handelsman DJ \& Celermajer DS. Prospective study of effect of androgens on serum inflammatory markers in men. Arteriosclerosis, Thrombosis and Vascular Biology 200222 1136-1141.

Received 12 December 2006

Accepted 15 February 2007 